\title{
Alain Cullière, Jean d'Arras et Odinet Basset, imprimeurs à Metz (1563-1564)
}

\section{Filippo Fonio}

\section{(2) OpenEdition}

1 Journals

\section{Edizione digitale}

URL: http://journals.openedition.org/studifrancesi/27431

DOI: 10.4000/studifrancesi.27431

ISSN: 2421-5856

\section{Editore}

Rosenberg \& Sellier

\section{Edizione cartacea}

Data di pubblicazione: 31 décembre 2006

Paginazione: 592-593

ISSN: 0039-2944

\section{Notizia bibliografica digitale}

Filippo Fonio, « Alain Cullière, Jean d'Arras et Odinet Basset, imprimeurs à Metz (1563-1564) », Studi

Francesi [Online], 150 (L | III) | 2006, online dal 30 novembre 2015, consultato il 08 novembre 2020.

URL : http://journals.openedition.org/studifrancesi/27431 ; DOI : https://doi.org/10.4000/

studifrancesi.27431

\section{Questo documento è stato generato automaticamente il 8 novembre 2020.}

\section{(c) (1)}

Studi Francesi è distribuita con Licenza Creative Commons Attribuzione - Non commerciale - Non opere derivate 4.0 Internazionale. 


\title{
Alain Cullière, Jean d'Arras et Odinet Basset, imprimeurs à Metz (1563-1564)
}

\author{
Filippo Fonio
}

\section{NOTIZIA}

ALAIN CULLIÈRE, Jean d'Arras et Odinet Basset, imprimeurs à Metz (1563-1564), «Bibliothèque d'Humanisme et Renaissance», LXVII, 3 (2005), pp. 673-700.

1 Lo studioso propone una ricca documentazione sulla stamperia di Jean d'Arras a Metz. Inviato come apprendista ad Anversa dove viene incarcerato per aver stampato un pamphlet giudicato eretico, Jean d'Arras fa ritorno a Metz, aprendovi una propria stamperia, nel dirigere la quale è coadiuvato da Odinet Basset. Jean d'Arras scomparso prematuramente, per qualche tempo la stamperia continua a lavorare, e le iniziative editoriali in corso alla morte del proprietario vengono portate a termine. La breve parabola dell'impresa di Jean d'Arras costituisce un tassello di rilievo per comprendere la situazione dell'editoria nel secondo Cinquecento nelle regioni ai confini dell'Impero. Jean d'Arras, stampatore riformato, e i suoi torchi si prestano non soltanto alla propaganda religiosa, facendo della stamperia in un certo senso un organo cittadino. In appendice le schede bibliografiche dei volumi stampati da Jean d'Arras ad Anversa e a Metz, e delle altre iniziative editoriali realizzate nella stamperia. 